\title{
Factors Associated with PMTCT Cascade Completion in Four African Countries
}

\author{
Jodie Dionne-Odom, ${ }^{1}$ Thomas K. Welty, ${ }^{2}$ Andrew O. Westfall, ${ }^{1}$ Benjamin H. Chi, ${ }^{3}$ \\ Didier Koumavi Ekouevi, ${ }^{4,5}$ Margaret Kasaro, ${ }^{3}$ Pius M. Tih, ${ }^{2}$ and Alan T. N. Tita ${ }^{1}$
}

${ }^{1}$ University of Alabama at Birmingham, Birmingham, AL, USA

${ }^{2}$ Cameroon Baptist Convention Health Services (CBCHS), Bamenda, Cameroon

${ }^{3}$ University of North Carolina at Chapel Hill, Chapel Hill, NC, USA

${ }^{4}$ Research Center INSERM U1219, ISPED, Université de Bordeaux, Bordeaux, France

${ }^{5}$ PAC-CI Program, ANRS Site, Abidjan, Côte d'Ivoire

Correspondence should be addressed to Jodie Dionne-Odom; jdionne@uabmc.edu

Received 22 June 2016; Revised 7 September 2016; Accepted 10 October 2016

Academic Editor: Glenda Gray

Copyright (C) 2016 Jodie Dionne-Odom et al. This is an open access article distributed under the Creative Commons Attribution License, which permits unrestricted use, distribution, and reproduction in any medium, provided the original work is properly cited.

\begin{abstract}
Background. Many countries are working to reduce or eliminate mother-to-child transmission (MTCT) of HIV. Prevention efforts have been conceptualized as steps in a cascade but cascade completion rates during and after pregnancy are low. Methods. A cross-sectional survey was performed across 26 communities in Cameroon, Cote d'Ivoire, South Africa, and Zambia. Women who reported a pregnancy within two years were enrolled. Participant responses were used to construct the PMTCT cascade with all of the following steps required for completion: at least one antenatal visit, HIV testing performed, HIV testing result received, initiation of maternal prophylaxis, and initiation of infant prophylaxis. Factors associated with cascade completion were identified using multivariable logistic regression modeling. Results. Of 976 HIV-infected women, only 355 (36.4\%) completed the PMTCT cascade. Although most women (69.2\%) did not know their partner's HIV status; awareness of partner HIV status was associated with cascade completion (aOR 1.4, 95\% CI 1.01-2.0). Completion was also associated with receiving an HIV diagnosis prior to pregnancy compared with HIV diagnosis during or after pregnancy (aOR 14.1, 95\% CI 5.2-38.6). Conclusions. Pregnant women with HIV infection in Africa who were aware of their partner's HIV status and who were diagnosed with HIV before pregnancy were more likely to complete the PMTCT cascade.
\end{abstract}

\section{Background}

The worldwide elimination of mother-to-child transmission of HIV is an ambitious goal. Despite significant progress toward this goal over the past decade, most of the 220,000 new pediatric HIV infections in 2014 were attributed to vertical transmission [1]. Successful prevention of mother-tochild HIV transmission (PMTCT) requires early HIV diagnosis, consistent access to antiretroviral (ART) medications, and engagement in care during and after pregnancy [2]. Current international guidelines recommend lifelong ART for all pregnant women (PMTCT World Health Organization (WHO) Option $\mathrm{B}+$ ) and highlight the importance of retention in care to improve maternal and child health
$[3,4]$. The HIV PMTCT cascade provides an effective tool to visualize prevention efforts in pregnant women and to identify opportunities for improvement as highlighted by the landmark PEARL study (PMTCT Effectiveness in Africa: Research and Linkages to Care) which took place in four African countries. The PEARL study had two components: a community-based component with household-level surveys and a facility-based component with the collection of cord blood to measure nevirapine levels. It was designed to measure infant HIV-free survival at the population level. It also estimated the effectiveness of PMTCT programs by comparing HIV pregnancy outcomes in Sub-Saharan Africa collected from women at the facility level compared to women surveyed in the "real world" community setting. 
This study defined the PMTCT cascade as five essential and sequential steps: at least one antenatal care (ANC) visit, an HIV test performed, the HIV test result received, initiation of maternal ART prophylaxis, and initiation of infant ART prophylaxis [5]. Cascade completion rates are suboptimal among HIV-infected women during and after pregnancy [69]. The completion rate in the facility component of the PEARL study across all sites was 51\% and in another study in South Africa, $58 \%$ of HIV-infected pregnant women in care were lost to follow-up (LFU) by 6 months after delivery $[5,10]$. Certain factors have been associated with LFU: younger age ( $<25$ years old), ART initiation during pregnancy, and pregnancy itself [11-14]. On the other hand, improved PMTCT cascade completion rates have been associated with male partner involvement, couples HIV counseling and testing programs, and HIV status disclosure [15-18]. Understanding the predictors of cascade completion can be used to improve PMTCT programs and maternal and infant HIV-associated outcomes.

In a recent analysis of the PEARL community-level data by Chi et al., the cascade completion rate was lower (36.4\%) than the rate calculated with facility level data (51\%) although both were suboptimal despite high rates of access to ANC care (97.3\%) and facility deliveries (93.2\%) [19]. For this analysis, we used data from the community-based component of the PEARL study and sought to identify individual characteristics associated with PMTCT cascade completion.

\section{Methods}

2.1. Study Design. The PEARL study was conducted in Cameroon, Cote d'Ivoire, South Africa, and Zambia during 2007-2009. The 165-question community-based household survey was administered by trained study teams. Households in chosen PMTCT program catchment areas were randomly selected for participation and blood was collected from mother-infant pairs for HIV testing [19]. Women who reported a birth in the past 24 months were eligible to participate and the PMTCT cascade was recreated for women with HIV infection based on their responses to survey questions. Standard of care for PMTCT medications varied by country, but, overall, $36 \%$ of women received prophylaxis with antenatal zidovudine and peripartum nevirapine, 37\% received peripartum nevirapine only, $18 \%$ received combination therapy (defined as receiving more than one antiretroviral drug to treat HIV), and $76.3 \%$ of infants received prophylaxis with zidovudine and nevirapine.

2.2. Study Outcome. Successful completion of the PMTCT cascade was the main study outcome and it required completion of five steps. The five-step cascade was defined as follows: having had at least one ANC visit, having an HIV test performed, receipt of the HIV test result, initiation of maternal antiretroviral prophylaxis, and initiation of infant antiretroviral prophylaxis.

2.3. Independent Variables. Available sociodemographic and healthcare-related variables were examined for potential association with cascade completion. Sociodemographic variables included age, marital status, education, parity, household size (total number of persons), source of household water, ownership of a mode of transportation (bicycle, motorcycle, or car), and current employment outside the home. Country of origin was not included as a variable since it was a stratification factor in the analysis.

Healthcare-related variables included timing of HIV diagnosis (before, during, or after last pregnancy), partner HIV testing and status (with separate multivariable models created for HIV status known/unknown and HIV test positive/negative/unknown), method used (ever) for family planning (modern, traditional, or none), gestational age at initial antenatal care visit (self-report), ANC location (hospital, health center, health post, or other), and ANC facility type (public facility, faith-based organizational facility, or other). The family planning variable was categorized into modern or traditional methods using standard definitions. Modern methods were defined according to the WHO definition as sterilization, intrauterine device (IUD), implants, injectables, lactational amenorrhea, pill, or condoms. Pill and condoms were grouped as short-acting modern methods. Traditional methods were defined as natural family planning or withdrawal. Information about HIV status disclosure by participants was not available.

2.4. Data Analysis. Baseline characteristics of women were compiled with percentages for categorical variables. The denominator used for the cascade was the 976 women identified with HIV infection with complete data from the community survey. Univariate and multivariable (MV) logistic regression analysis was used to create a model with the outcome of successful cascade completion. Variables were chosen for inclusion in the final MV analysis based on significance in the univariate model $(p<0.05)$ and factors associated with cascade completion in prior studies (age, marital status, education, socioeconomic status, and timing of ANC entry) regardless of univariate significance [8]. The model was stratified by country with a fixed effects conditional logistic regression approach where each stratus was allowed its own intercept. The sample size was not sufficient for analysis at the individual country level. All analyses were performed with SAS 9.4 (Cary, NC).

2.5. Ethics. The primary study was approved by the institutional review boards of the University of Alabama at Birmingham (UAB), US Centers for Disease Control (CDC), and local research ethics committees in Cameroon, Zambia, South Africa, and Cote d'Ivoire. A waiver was obtained from the Cameroon Baptist Convention Health Services (CBCHS) IRB to perform this additional analysis using a deidentified, released dataset.

\section{Results}

From April 2007 to March 2009, 7985 mother-infant pairs were enrolled in the four-country household-level community-based component of the PEARL study and 1014 women (12.7\%) tested positive for HIV. Complete data available for $976 \mathrm{HIV}$-infected women comprised our study population. 


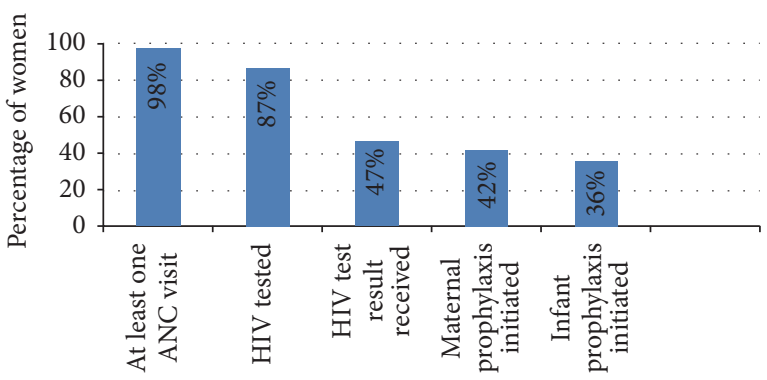

FIgURE 1: PEARL PMTCT cascade among 976 HIV-infected pregnant women in four African countries (data from Chi et al. [19]).

In this group, 355 (36.4\%) completed every step of the cascade (Figure 1). As reported previously by Chi et al., in relation to the study population as a whole, $98 \%$ of women attended at least $1 \mathrm{ANC}$ visit, $87 \%$ were tested for HIV, $47 \%$ received a positive HIV test result, $42 \%$ initiated maternal prophylaxis, and $36 \%$ initiated infant prophylaxis [19]. The most significant dropout was among women who reported that they were tested for HIV but did not receive the results.

The characteristics of women who completed the cascade versus those who did not are shown in Table 1. Overall, the median age of the cohort was 27 and most participants were from Zambia (45.5\%) or South Africa (37.4\%). Most women were married $(56 \%)$, had attended at least secondary school (55.9\%), and had never used birth control (43.6\%), and the median parity was 2 . A majority did not own a method of transportation $(75.7 \%)$ and nearly all women reported attending antenatal care at least once. Most women presented for ANC care in the 2nd trimester $(67.9 \%)$ at a governmental health center clinic and nearly 1 in 4 women were diagnosed with HIV during the most recent pregnancy. Nearly $70 \%$ of women did not know the HIV status of their male partner. In general, sociodemographic characteristics did not appear to differ by cascade completion status whereas several healthrelated factors including the timing of HIV diagnosis, partner HIV testing, use of birth control, ANC location, and facility type were significantly different (Table 1).

In the univariate analysis, the strongest association with cascade completion was in women diagnosed with HIV prior to pregnancy compared with HIV diagnosis during or after pregnancy (OR 12.3, 95\% CI 5.3-28.6) (Table 2). Other factors associated with cascade completion included age above 30 , parity of 4 , household size above 3 , and use of longacting modern birth control methods. Maternal employment, household water source, and ownership of a television or cellphone were included in the model but were not associated with cascade completion. Due to collinearity between ANC location and facility type, only facility type was included in the MV model.

The MV analysis based on 843 observations (Table 2) shows a significant association between cascade completion and awareness of partner HIV status (aOR 1.4, 95\% CI 1.012.0), HIV diagnosis prior to pregnancy (aOR 14.1, 95\% CI 5.238.6), and use (ever) of a long-acting method of contraception (aOR 2.0, 95\% CI 1.3-3.0). When the multivariable analysis was repeated using a three-level variable for partner HIV status (negative/positive/unknown), having an HIV-positive partner was associated with cascade completion compared to having an HIV-uninfected partner (OR 6.1, 95\% CI 3.012.3). In this model, other findings were similar except for an association of cascade completion with household size of 4 persons (compared to 1-2) with an OR 2.9, 95\% CI 1.02-8.18 and a lack of association with owning a means of transportation or having ANC at a facility that was run neither by the government nor an FBO.

\section{Discussion}

The PMTCT cascade completion rate from entry into ANC care to receipt of infant antiretroviral prophylaxis was only $36.4 \%$ using community-based survey data. This rate is comparable to more recent studies in Africa showing cascade completion rates ranging from 11 to $70 \%$ [20-23]. Fortunately, access to HIV testing and antiretroviral therapy in pregnancy is improving as PMTCT programs are upscaled worldwide [3]. Antenatal HIV testing is not yet universal but $77 \%$ of pregnant women with known HIV infection had access to antiretrovirals in 2015 [24]. This number varies by region with 90\% ART coverage for pregnant women living with HIV in East/South Africa but only $48 \%$ coverage among pregnant women in West/Central Africa. These numbers also underestimate the need for ART since many women are unaware of their infection. Although PMTCT can be incorporated into routine antenatal care, studies now show that many HIV-infected women who are engaged in care during pregnancy are lost to follow-up during the postpartum period [6, 25-28]. This creates an important barrier to maintaining virologic suppression in women with multiple births and more effective PMTCT programs are needed to facilitate long-term retention in care and reach the ambitious UN AIDS target of 90-90-90 by 2030 .

Our study is the first to our knowledge to document the importance of awareness of partner HIV status in terms of PMTCT cascade completion. Nearly $70 \%$ of women with HIV were not aware of their partner's HIV status in our study and $41 \%$ of women with a recent pregnancy in South Africa were similarly unaware [29]. Whether this beneficial effect is mediated via a reduction in stigma or an increase in support is not clear but cascade completion rates were highest among women with concordant, HIV-infected male partners. The importance of male partner involvement with the PMTCT process has recently been recognized and women surveyed have been strongly supportive of this concept [3032]. Programs offering couples voluntary counseling and testing in the antenatal clinic setting have shown mixed efficacy, with improved infant nevirapine use in Kenya but not in Rwanda or Zambia [16, 33, 34]. Awareness of partner HIV status has also been associated with other beneficial outcomes among women with HIV, such as higher facility delivery rates [35]. In Kenya, HIV-infected pregnant women who reported that their partner had been tested for HIV had lower rates of vertical transmission and infant mortality, but awareness of partner HIV status was not captured [36]. Current interventions to improve PMTCT partner testing include mailed invitations and home-based HIV testing procedures [37-41]. 
TABLE 1: Baseline characteristics of survey respondents* $(n=976)$.

\begin{tabular}{|c|c|c|c|c|}
\hline Variable & $\begin{array}{l}\text { Completed PMTCT cascade } \\
(n=355) n(\%)\end{array}$ & $\begin{array}{l}\text { Did not complete PMTCT } \\
\text { cascade }(n=621) n(\%)\end{array}$ & $p$ value $^{* *}$ & $\begin{array}{r}\text { Total } \\
n(\%)\end{array}$ \\
\hline \multicolumn{5}{|l|}{ Sociodemographics } \\
\hline Country of origin & & & $<0.0001$ & \\
\hline Cameroon & $55(15.4)$ & $59(9.5)$ & & $114(11.7)$ \\
\hline Cote d'Ivoire & $1(0.3)$ & $52(8.4)$ & & $53(5.4)$ \\
\hline South Africa & $112(31.6)$ & $253(40.7)$ & & $365(37.4)$ \\
\hline Zambia & $187(52.7)$ & $257(41.4)$ & & $444(45.5)$ \\
\hline Age & & & 0.09 & \\
\hline$<20$ & $11(3.1)$ & $37(6)$ & & $48(4.9)$ \\
\hline $20-30$ & $228(64.2)$ & $409(65.9)$ & & $637(65.3)$ \\
\hline$>30$ & $116(32.7)$ & $175(28.1)$ & & $291(29.8)$ \\
\hline Marital status & & & 0.68 & \\
\hline Married & $222(62.7)$ & $321(52.2)$ & & $543(56)$ \\
\hline Living together & $20(5.7)$ & $62(10.1)$ & & $82(8.5)$ \\
\hline Divorced & $10(2.8)$ & $10(1.6)$ & & $20(2)$ \\
\hline Separated & $17(4.8)$ & $42(6.8)$ & & $59(6.1)$ \\
\hline Widowed & $18(5.1)$ & $29(4.7)$ & & $47(4.9)$ \\
\hline No partner & $67(18.9)$ & $151(24.6)$ & & $218(22.5)$ \\
\hline Education & & & 0.56 & \\
\hline None/primary & $157(44.4)$ & $270(44)$ & & $427(44.1)$ \\
\hline Secondary or higher & $197(55.6)$ & $344(56)$ & & $541(55.9)$ \\
\hline Parity & & & 0.08 & \\
\hline 1 & $89(25.8)$ & $200(33.4)$ & & $289(30.6)$ \\
\hline 2 & $104(30.1)$ & $182(30.5)$ & & $286(30.3)$ \\
\hline 3 & $73(21.2)$ & $105(17.6)$ & & $178(18.9)$ \\
\hline 4 & $44(12.8)$ & $51(8.5)$ & & $95(10.1)$ \\
\hline $5+$ & $35(10.1)$ & $60(10)$ & & $95(10.1)$ \\
\hline Household size & & & 0.05 & \\
\hline $1-2$ & $53(15.1)$ & $135(22)$ & & $188(19.5)$ \\
\hline 3 & $93(26.5)$ & $198(32.3)$ & & $291(30.2)$ \\
\hline 4 & $101(28.8)$ & $141(23)$ & & $242(25.1)$ \\
\hline $5+$ & $104(29.6)$ & $139(22.7)$ & & $243(25.2)$ \\
\hline Source of water & & & 0.33 & \\
\hline Public tap & $120(33.8)$ & $145(23.4)$ & & $265(27.2)$ \\
\hline $\begin{array}{l}\text { Protected well or piped } \\
\text { into plot }\end{array}$ & $131(36.9)$ & $277(44.6)$ & & $408(41.8)$ \\
\hline Piped into house & $63(17.7)$ & $120(19.3)$ & & $183(18.7)$ \\
\hline Other & 41 (11.6) & 79 (12.7) & & $120(12.3)$ \\
\hline Own a television & & & 0.97 & \\
\hline Yes & $196(55.8)$ & $373(60.6)$ & & $569(58.8)$ \\
\hline No & $155(44.2)$ & $243(39.4)$ & & $398(41.2)$ \\
\hline Own a cell phone & & & 0.26 & \\
\hline Yes & $252(71.6)$ & $440(71)$ & & $692(71.2)$ \\
\hline No & $100(28.4)$ & $180(29)$ & & $280(28.8)$ \\
\hline
\end{tabular}


TABLE 1: Continued.

\begin{tabular}{|c|c|c|c|c|}
\hline Variable & $\begin{array}{l}\text { Completed PMTCT cascade } \\
\qquad(n=355) n(\%)\end{array}$ & $\begin{array}{l}\text { Did not complete PMTCT } \\
\text { cascade }(n=621) n(\%)\end{array}$ & $p$ value $* *$ & $\begin{array}{r}\text { Total } \\
n(\%)\end{array}$ \\
\hline $\begin{array}{l}\text { Current employment Outside } \\
\text { home }\end{array}$ & & & 0.71 & \\
\hline Yes & $142(40.2)$ & $225(36.3)$ & & $367(37.8)$ \\
\hline No & $211(59.8)$ & $394(63.7)$ & & $605(62.2)$ \\
\hline Own a method of transportation & & & 0.08 & \\
\hline Yes & $77(22.5)$ & $156(25.4)$ & & $233(24.3)$ \\
\hline No & $266(77.5)$ & $459(74.6)$ & & $725(75.7)$ \\
\hline \multicolumn{5}{|l|}{ Health related } \\
\hline Timing of HIV diagnosis & & & $<0.01$ & \\
\hline Before pregnancy & $43(12.6)$ & $7(1.1)$ & & $50(5.2)$ \\
\hline During pregnancy & $175(51.2)$ & $40(6.6)$ & & $215(22.5)$ \\
\hline After pregnancy & $124(36.2)$ & $565(92.3)$ & & $689(72.3)$ \\
\hline Partner HIV testing & & & $<0.01$ & \\
\hline Negative & $41(11.6)$ & $120(19.5)$ & & $161(16.6)$ \\
\hline Positive & $100(28.3)$ & $38(6.2)$ & & $138(14.2)$ \\
\hline Not tested/do not know & $212(60.1)$ & $458(74.3)$ & & $670(69.2)$ \\
\hline Use of birth control (ever) & & & $<0.01$ & \\
\hline \multicolumn{5}{|l|}{ Modern method } \\
\hline Injectables/implants & $119(33.7)$ & $156(25.3)$ & & $275(28.4)$ \\
\hline Pill & $68(19.3)$ & $123(19.9)$ & & $191(19.7)$ \\
\hline Condoms & $37(10.5)$ & $26(4.2)$ & & $63(6.5)$ \\
\hline $\begin{array}{l}\mathrm{M} / \mathrm{F} \text { sterilization or } \\
\text { hysterectomy }\end{array}$ & $2(0.6)$ & $4(0.7)$ & & $6(0.6)$ \\
\hline Intrauterine device & $1(0.3)$ & $3(0.5)$ & & $4(0.4)$ \\
\hline $\begin{array}{l}\text { Lactational } \\
\text { amenorrhea }\end{array}$ & $1(0.3)$ & $2(0.3)$ & & $3(0.3)$ \\
\hline \multicolumn{5}{|l|}{$\begin{array}{l}\text { Traditional or no } \\
\text { method }\end{array}$} \\
\hline No method & $125(35.3)$ & $298(48.3)$ & & $423(43.6)$ \\
\hline NFP or withdrawal & $0(0)$ & $5(0.8)$ & & $5(0.5)$ \\
\hline Timing of ANC entry & & & 0.29 & \\
\hline 1st trimester & $56(15.8)$ & $129(21.7)$ & & $185(19.5)$ \\
\hline 2nd trimester & $254(71.6)$ & $390(65.8)$ & & $644(67.9)$ \\
\hline 3rd trimester & $45(12.6)$ & $74(12.5)$ & & $119(12.6)$ \\
\hline ANC location & & & $<0.01$ & \\
\hline Hospital & $51(14.4)$ & $88(14.2)$ & & $139(14.2)$ \\
\hline Health center & $291(82)$ & $460(77)$ & & $751(77)$ \\
\hline Health post & $8(2.3)$ & $22(3.1)$ & & $30(3.1)$ \\
\hline Other & $5(1.4)$ & $51(5.7)$ & & $56(5.7)$ \\
\hline ANC facility type & & & $<0.01$ & \\
\hline Governmental & $312(87.9)$ & $529(85.2)$ & & $841(86.2)$ \\
\hline Faith based organization & $38(10.7)$ & $41(6.6)$ & & $79(8.1)$ \\
\hline Other & $5(1.4)$ & $51(8.2)$ & & $56(5.7)$ \\
\hline
\end{tabular}

${ }^{*}$ Missing values: marital status 7 , education 8 , parity 33 , household size 12 , own a television 9 , own a cell phone 4 , current employment outside home 4 , own a method of transportation 18, timing of HIV diagnosis 22, partner HIV testing 7, use of birth control (ever) 6, and timing of ANC entry 28.

${ }^{* *} p$ values calculated from univariate logistic regression models which included site as a stratification factor. The $p$ value for family planning compares modern methods to traditional/no method.

PMTCT: prevention of mother to child HIV transmission, ANC: antenatal clinic, and NFP: natural family planning. 
TABLE 2: Factors associated with cascade completion in the PEARL study ${ }^{* *}$.

\begin{tabular}{|c|c|c|}
\hline Variable & $\begin{array}{l}\text { Univariate analysis } \\
\text { OR }(95 \% \mathrm{CI})\end{array}$ & $\begin{array}{c}\text { Multivariable analysis } \\
\text { OR }(95 \% \mathrm{CI}) \\
n=843 \\
\end{array}$ \\
\hline \multicolumn{3}{|l|}{ Maternal age (years) } \\
\hline$<20$ & Ref & Ref \\
\hline $20-30$ & $1.8(0.9-3.7)$ & $1.8(0.8-4.2)$ \\
\hline$>30$ & $2.2(1.1-4.5)^{*}$ & $1.9(0.8-4.5)$ \\
\hline \multicolumn{3}{|l|}{ Marital status } \\
\hline No partner & Ref & Ref \\
\hline Partner & $1.1(0.8-1.6)$ & $0.8(0.5-1.3)$ \\
\hline \multicolumn{3}{|l|}{ Education } \\
\hline None/primary & Ref & Ref \\
\hline Secondary or higher & $1.1(0.8-1.5)$ & $1.1(0.8-1.5)$ \\
\hline \multicolumn{3}{|l|}{ Parity } \\
\hline 1 & Ref & Ref \\
\hline 2 & $1.3(0.9-1.8)$ & $0.8(0.5-1.4)$ \\
\hline 3 & $1.4(0.9-2.1)$ & $0.7(0.3-1.4)$ \\
\hline 4 & $1.9(1.2-3.2)^{*}$ & $1(0.4-2.5)$ \\
\hline $5+$ & $1(0.6-1.7)$ & $0.5(0.2-1.4)$ \\
\hline \multicolumn{3}{|l|}{ Household size } \\
\hline $1-2$ & Ref & Ref \\
\hline 3 & $1.2(0.8-1.8)$ & $1.4(0.7-2.7)$ \\
\hline 4 & $1.7(1.1-2.5)^{*}$ & $2.3(1.0-5.4)$ \\
\hline $5+$ & $1.6(1.04-2.4)^{*}$ & $2.3(0.8-6.6)$ \\
\hline \multicolumn{3}{|l|}{ Source of water } \\
\hline Protected well or piped into plot & Ref & \multirow{4}{*}{$\mathrm{N} / \mathrm{A}$} \\
\hline Piped into house & $1.1(0.7-1.6)$ & \\
\hline Public tap & $1.2(0.9-1.8)$ & \\
\hline Other & $0.8(0.5-1.3)$ & \\
\hline \multicolumn{3}{|l|}{ Own a television } \\
\hline No & Ref & \multirow{2}{*}{$\mathrm{N} / \mathrm{A}$} \\
\hline Yes & $1(0.8-1.3)$ & \\
\hline \multicolumn{3}{|l|}{ Own a cellphone } \\
\hline No & Ref & Ref \\
\hline Yes & $1.2(0.9-1.6)$ & $1.3(0.9-1.9)$ \\
\hline \multicolumn{3}{|l|}{ Employment } \\
\hline No & Ref & \multirow{2}{*}{$\mathrm{N} / \mathrm{A}$} \\
\hline Yes & $1(0.7-1.3)$ & \\
\hline \multicolumn{3}{|l|}{ Own a method of transportation } \\
\hline No & Ref & Ref \\
\hline Yes & $0.8(0.5-1)$ & $0.7(0.5-0.98)^{*}$ \\
\hline \multicolumn{3}{|l|}{ Timing of HIV diagnosis } \\
\hline During/after pregnancy & Ref & Ref \\
\hline Before pregnancy & $12.3(5.3-28.6)^{*}$ & $14.1(5.2-38.6)^{*}$ \\
\hline \multicolumn{3}{|l|}{ Partner HIV status } \\
\hline Unknown & Ref & Ref \\
\hline Known & $1.7(1.3-2.2)^{*}$ & $1.4(1.01-2.0)^{*}$ \\
\hline
\end{tabular}


TABLE 2: Continued.

\begin{tabular}{|c|c|c|}
\hline Variable & $\begin{array}{l}\text { Univariate analysis } \\
\text { OR }(95 \% \text { CI })\end{array}$ & $\begin{array}{c}\text { Multivariable analysis } \\
\text { OR }(95 \% \mathrm{CI}) \\
n=843\end{array}$ \\
\hline \multicolumn{3}{|l|}{ Family planning } \\
\hline Traditional/none & Ref & Ref \\
\hline Short acting modern method & $1.3(1-1.9)$ & $1.3(0.8-1.9)$ \\
\hline Long acting modern method & $2.3(1.6-3.2)^{*}$ & $2.0(1.3-3.0)^{*}$ \\
\hline \multicolumn{3}{|l|}{ Timing of ANC entry } \\
\hline 1st trimester & Ref & Ref \\
\hline 2nd trimester & $1.3(0.9-1.9)$ & $1.3(0.9-2.0)$ \\
\hline 3rd trimester & $1.4(0.9-2.3)$ & $1.3(0.7-2.2)$ \\
\hline \multicolumn{3}{|l|}{ ANC location } \\
\hline Health center & Ref & \multirow{4}{*}{ N/A } \\
\hline Hospital & $1.1(0.7-1.6)$ & \\
\hline Health post & $1.2(0.4-3.5)$ & \\
\hline Other & $0.2(0.1-0.5)^{*}$ & \\
\hline \multicolumn{3}{|l|}{ ANC facility type } \\
\hline Governmental & Ref & Ref \\
\hline Faith based organization & $1.2(0.7-1.9)$ & $1.2(0.7-2.1)$ \\
\hline Other & $0.2(0.1-0.5)^{*}$ & $0.3(0.1-0.9)^{*}$ \\
\hline
\end{tabular}

Although our study did not capture disclosure information, HIV status disclosure during pregnancy (to anyone, but particularly to the male partner) has been associated with ARV use in PMTCT $[15,42,43]$.

HIV diagnosis prior to pregnancy was also independently associated with cascade completion. This supports similar findings in other studies [12, 14, 44]. Home-based and community-based HIV testing of young women have shown efficacy in facilitating early HIV diagnosis [20, 45]. Engagement in HIV care among women of childbearing age also improves PMTCT outcomes by reducing maternal viral load prior to the onset of pregnancy. This has been shown to minimize vertical transmission of HIV [46].

The significance noted for prior use of long-acting methods of contraception (including implants, injectables, and intrauterine devices) and cascade completion is interesting although this is likely a marker for health-seeking behavior or improved access to healthcare. This relationship persisted when adjusted for education and measures of household wealth. The negative association of cascade completion with ownership of a car, motorcycle, or bicycle is surprising but this may be explained by the distance from home to the healthcare facility or urban/rural residence (factors not captured in our analysis). In the univariate model, older age ( $>30)$ and larger household size ( $>3$ persons) were associated with cascade completion but these did not persist in the adjusted model.

The strengths of this study include the large sample size with surveys administered at the community level in four African countries. This was devised to be more representative of the general population of women with a recent pregnancy. Study limitations include the fact that surveys were conducted in different settings in 2007-2009, an earlier era in terms of antiretroviral management and prevention of vertical transmission. There was less representation from Cameroon and Cote d'Ivoire in the study numbers. Since the currently recommended PMTCT regimen is daily, lifelong combination antiretroviral therapy (a more complex regimen compared to single dose nevirapine) and long-term engagement in HIV care are even more critical today than they were at the time of the survey. Many individual factors associated with cascade completion are expected to be similar over time among pregnant women in Africa. The underlying effects of stigma and HIV status disclosure with respect to the cascade were not assessed with the survey questionnaire.

\section{Conclusions}

Improved completion rates of the PMTCT cascade are necessary to reduce vertical HIV transmission in sub-Saharan Africa. Awareness of male partner HIV status, prepregnancy HIV diagnosis, and the use of long-term contraceptive methods were associated with cascade completion in this study. These may be markers for improved access to care and health literacy. Interventions targeting male partner testing and early HIV diagnosis should be evaluated to define their efficacy in increasing completion of the PMTCT cascade.

\section{Competing Interests}

The authors declare that there are no competing interests regarding the publication of this paper. 


\section{References}

[1] UN AIDS, HIV/AIDS Fact Sheet, 2015.

[2] A. Spensley, T. Sripipatana, A. N. Turner, C. Hoblitzelle, J. Robinson, and C. Wilfert, "Preventing mother-to-child transmission of HIV in resource-limited settings: the Elizabeth glaser pediatric AIDS foundation experience," American Journal of Public Health, vol. 99, no. 4, pp. 631-637, 2009.

[3] UN AIDS Report-HIV/AIDS Treatment 2015, http://www.unaids.org/sites/default/files/media_asset/JC2484_treatment-2015_ en_1.pdf.

[4] PEPFAR, PEPFAR Country/Regional Operational Plan (COP/ ROP) 2016 Guidance, 2016.

[5] E. M. Stringer, D. K. Ekouevi, D. Coetzee et al., "Coverage of nevirapine-based services to prevent mother-to-child HIV transmission in 4 African countries," The Journal of the American Medical Association, vol. 304, no. 3, pp. 293-302, 2010.

[6] C. Psaros, J. E. Remmert, D. R. Bangsberg, S. A. Safren, and J. A. Smit, "Adherence to HIV care after pregnancy among women in sub-saharan Africa: falling off the cliff of the treatment cascade," Current HIV/AIDS Reports, vol. 12, no. 1, pp. 1-5, 2015.

[7] J. B. Nachega, O. A. Uthman, J. Anderson et al., "Adherence to antiretroviral therapy during and after pregnancy in lowincome, middle-income, and high-income countries: a systematic review and meta-analysis," AIDS, vol. 26, no. 16, pp. 20392052, 2012.

[8] A. Gourlay, I. Birdthistle, G. Mburu, K. Iorpenda, and A. Wringe, "Barriers and facilitating factors to the uptake of antiretroviral drugs for prevention of mother-to-child transmission of HIV in sub-Saharan Africa: a systematic review," Journal of the International AIDS Society, vol. 16, Article ID 18588, 2013.

[9] C. M. Jodie Dionne-Odom, K. Jogerst, Z. Li et al., "Retention in care among HIV-infected pregnant women in haiti with PMTCT option B," AIDS Research and Treatment, vol. 2016, Article ID 6284290, 10 pages, 2016.

[10] K. Clouse, A. Pettifor, K. Shearer et al., "Loss to follow-up before and after delivery among women testing HIV positive during pregnancy in Johannesburg, South Africa," Tropical Medicine and International Health, vol. 18, no. 4, pp. 451-460, 2013.

[11] H. Tweya, S. Gugsa, M. Hosseinipour et al., "Understanding factors, outcomes and reasons for loss to follow-up among women in Option B+ PMTCT programme in Lilongwe, Malawi," Tropical Medicine \& International Health, vol. 19, no. 11, pp. 1360-1366, 2014.

[12] T. H. Boyles, L. S. Wilkinson, R. Leisegang, and G. Maartens, "Factors influencing retention in care after starting antiretroviral therapy in a rural South African programme," PLoS ONE, vol. 6, no. 5, Article ID e19201, 2011.

[13] P. M. Barker, W. Mphatswe, and N. Rollins, "Antiretroviral drugs in the cupboard are not enough: the impact of health systems' performance on mother-to-child transmission of HIV," Journal of Acquired Immune Deficiency Syndromes, vol. 56, no. 2, pp. e45-e48, 2011.

[14] L. Tenthani, A. D. Haas, H. Tweya et al., "Retention in care under universal antiretroviral therapy for HIV-infected pregnant and breastfeeding women ('Option B+') in Malawi,' AIDS, vol. 28, no. 4, pp. 589-598, 2014.

[15] M. Tam, A. Amzel, and B. R. Phelps, "Disclosure of HIV serostatus among pregnant and postpartum women in subSaharan Africa: a systematic review," AIDS Care, vol. 27 , no. 4 , pp. 436-450, 2015.
[16] M. Conkling, E. L. Shutes, E. Karita et al., “Couples' voluntary counselling and testing and nevirapine use in antenatal clinics in two African capitals: a prospective cohort study," Journal of the International AIDS Society, vol. 13, no. 1, article 10, 2010.

[17] J. Ambia and J. Mandala, "A systematic review of interventions to improve prevention of mother-to-child HIV transmission service delivery and promote retention," Journal of the International AIDS Society, vol. 19, no. 1, Article ID 20309, 2016.

[18] F. Morfaw, L. Mbuagbaw, L. Thabane et al., "Male involvement in prevention programs of mother to child transmission of HIV: a systematic review to identify barriers and facilitators," Systematic Reviews, vol. 2, article 5, 2013.

[19] B. H. Chi, P. M. Tih, A. Zanolini et al., "Implementation and operational research: reconstructing the PMTCT cascade using cross-sectional household survey data: the PEARL study," Journal of Acquired Immune Deficiency Syndromes, vol. 70, no. 1, pp. e5-e9, 2015.

[20] Y. Marcos, B. R. Phelps, and G. Bachman, "Community strategies that improve care and retention along the prevention of mother-to-child transmission of HIV cascade: a review," Journal of the International AIDS Society, vol. 15, supplement 2, Article ID 17394, 2012.

[21] K. Torpey, M. Kabaso, P. Kasonde et al., "Increasing the uptake of prevention of mother-to-child transmission of HIV services in a resource-limited setting," BMC Health Services Research, vol. 10, article 29, 2010.

[22] K. Klaus, J. Baldwin, R. Izurieta et al., "Reducing PMTCT Attrition: perspectives of HIV+women on the prevention of motherto-child HIV services in Addis Ababa, Ethiopia," Ethiopian medical journal, vol. 53, no. 2, pp. 91-104, 2015.

[23] E. L. Sibanda, I. V. D. Weller, J. G. Hakim, and F. M. Cowan, "The magnitude of loss to follow-up of HIV-exposed infants along the prevention of mother-to-child HIV transmission continuum of care: a systematic review and meta-analysis," AIDS, vol. 27, no. 17, pp. 2787-2797, 2013.

[24] UN AIDS, HIV Fact Sheet, 2016.

[25] K. Aebi-Popp, R. Kouyos, B. Bertisch et al., "Loss to followup of HIV-infected women after delivery: The Swiss HIV Cohort Study and the Swiss Mother and Child HIV Cohort Study," Journal of the International AIDS Society, vol. 17, no. 4, supplement 3, Article ID 19535, 2014.

[26] T. K. Welty, M. Bulterys, E. R. Welty et al., "Integrating prevention of mother-to-child HIV transmission into routine antenatal care: the key to program expansion in Cameroon," Journal of Acquired Immune Deficiency Syndromes, vol. 40, no. 4, pp. 486-493, 2005.

[27] J. W. Adams, K. A. Brady, Y. L. Michael, B. R. Yehia, and F. M. Momplaisir, "Postpartum engagement in HIV care: an important predictor of long-term retention in care and viral suppression," Clinical Infectious Diseases, vol. 61, no. 12, pp. 1880-1887, 2015.

[28] J. Dionne-Odom, C. Massaro, K. M. Jogerst et al., "Retention in care among HIV-infected pregnant women in haiti with PMTCT option B," AIDS Research and Treatment, vol. 2016, Article ID 6284290, 10 pages, 2016.

[29] L. T. Matthews, L. Moore, T. L. Crankshaw et al., "South Africans with recent pregnancy rarely know partner's HIV serostatus: implications for serodiscordant couples interventions," $B M C$ Public Health, vol. 14, no. 1, article 843, 2014.

[30] S. Brusamento, E. Ghanotakis, L. Tudor Car, M. H. vanVelthoven, A. Majeed, and J. Car, "Male involvement for increasing the effectiveness of prevention of mother-to-child HIV 
transmission (PMTCT) programmes," The Cochrane Database of Systematic Reviews, vol. 10, Article ID CD009468, 2012.

[31] G. N. Nkuoh, D. J. Meyer, and E. M. Nshom, "Women's attitudes toward their partners' involvement in antenatal care and prevention of mother-to-child transmission of HIV in Cameroon, Africa," Journal of Midwifery \& Women's Health, vol. 58, no. 1, pp. 83-91, 2013.

[32] J. Kashitala, N. Nyambe, S. Mwalo et al., "Is male involvement in ANC and PMTCT associated with increased facility-based obstetric delivery in pregnant women?" African Journal of Reproductive Health, vol. 19, no. 2, pp. 117-124, 2015.

[33] C. Farquhar, J. N. Kiarie, B. A. Richardson et al., "Antenatal couple counseling increases uptake of interventions to prevent HIV-1 transmission," Journal of Acquired Immune Deficiency Syndromes, vol. 37, no. 5, pp. 1620-1626, 2004.

[34] K. Semrau, L. Kuhn, C. Vwalika et al., "Women in couples antenatal HIV counseling and testing are not more likely to report adverse social events," AIDS, vol. 19, no. 6, pp. 603-609, 2005.

[35] J. Kinuthia, P. Kohler, J. Okanda, G. Otieno, F. Odhiambo, and G. John-Stewart, "A community-based assessment of correlates of facility delivery among HIV-infected women in western Kenya," BMC Pregnancy and Childbirth, vol. 15, article 46, 2015.

[36] A. Aluisio, B. A. Richardson, R. Bosire, G. John-Stewart, D. Mbori-Ngacha, and C. Farquhar, "Male antenatal attendance and HIV testing are associated with decreased infant HIV infection and increased HIV-free survival," Journal of Acquired Immune Deficiency Syndromes, vol. 56, no. 1, pp. 76-82, 2011.

[37] L. F. Jefferys, P. Nchimbi, P. Mbezi, J. Sewangi, and S. Theuring, "Official invitation letters to promote male partner attendance and couple voluntary HIV counselling and testing in antenatal care: an implementation study in Mbeya Region, Tanzania," Reproductive Health, vol. 12, article 95, 2015.

[38] A. O. Osoti, G. John-Stewart, J. N. Kiarie et al., "Home-based HIV testing for men preferred over clinic-based testing by pregnant women and their male partners, a nested crosssectional study," BMC Infectious Diseases, vol. 15, no. 1, article 298, 2015.

[39] A. N. Ladur, C. J. Colvin, and K. Stinson, "Perceptions of community members and healthcare workers on male involvement in prevention of mother-to-child transmission services in Khayelitsha, Cape Town, South Africa," PLoS ONE, vol. 10, no. 7, Article ID e0133239, 2015.

[40] C. Henley, G. Forgwei, T. Welty et al., "Scale-up and casefinding effectiveness of an HIV partner services program in Cameroon: an innovative HIV prevention intervention for developing countries," Sexually Transmitted Diseases, vol. 40, no. 12, pp. 909-914, 2013.

[41] A. O. Osoti, G. John-Stewart, J. Kiarie et al., "Home visits during pregnancy enhance male partner HIV counselling and testing in Kenya: a randomized clinical trial," AIDS, vol. 28, no. 1, pp. 95-103, 2014.

[42] S. A. Spangler, M. Onono, E. A. Bukusi, C. R. Cohen, and J. M. Turan, "HIV-positive status disclosure and use of essential PMTCT and maternal health services in rural Kenya," Journal of Acquired Immune Deficiency Syndromes, vol. 67, supplement 4, pp. S235-S242, 2014.

[43] I. Kirsten, J. Sewangi, A. Kunz et al., "Adherence to combination prophylaxis for prevention of mother-to-child-transmission of HIV in Tanzania," PLoS ONE, vol. 6, no. 6, Article ID e21020, 2011.
[44] F. M. Momplaisir, K. A. Brady, T. Fekete, D. R. Thompson, A. D. Roux, and B. R. Yehia, "Time of HIV diagnosis and engagement in prenatal care impact virologic outcomes of pregnant women with HIV," PLoS ONE, vol. 10, no. 7, Article ID e0132262, 2015.

[45] S. Ndege, S. Washington, A. Kaaria et al., "HIV prevalence and antenatal care attendance among pregnant women in a large home-based HIV counseling and testing program in Western Kenya," PLoS ONE, vol. 11, no. 1, Article ID e0144618, 2016.

[46] L. Mandelbrot, R. Tubiana, J. Le Chenadec et al., "No perinatal HIV-1 transmission from women with effective antiretroviral therapy starting before conception," Clinical Infectious Diseases, vol. 61, no. 11, pp. 1715-1725, 2015. 


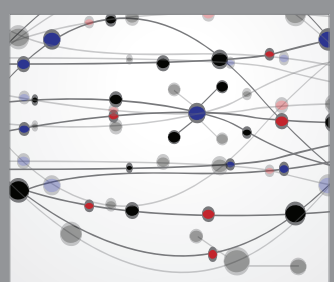

The Scientific World Journal
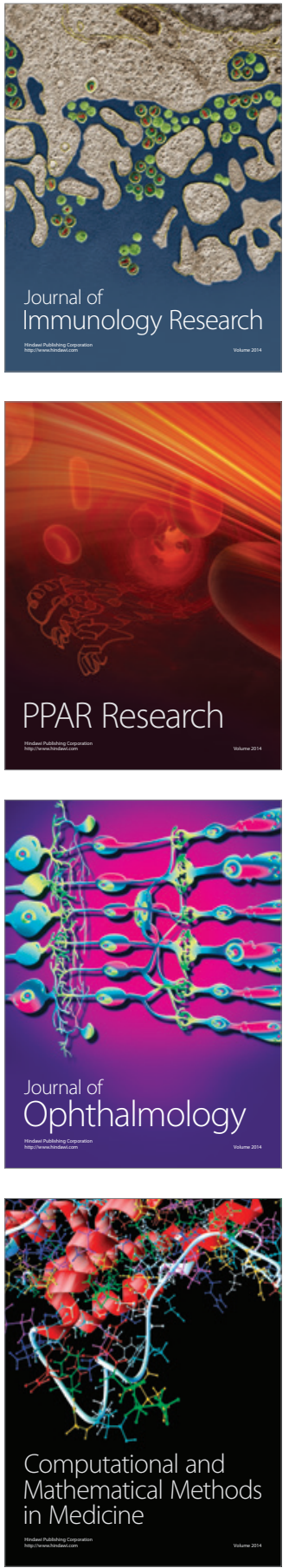

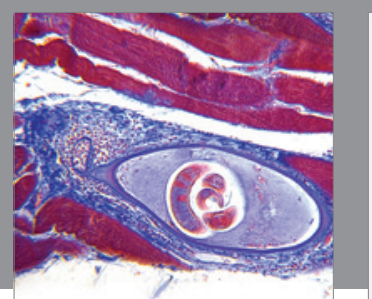

Gastroenterology Research and Practice

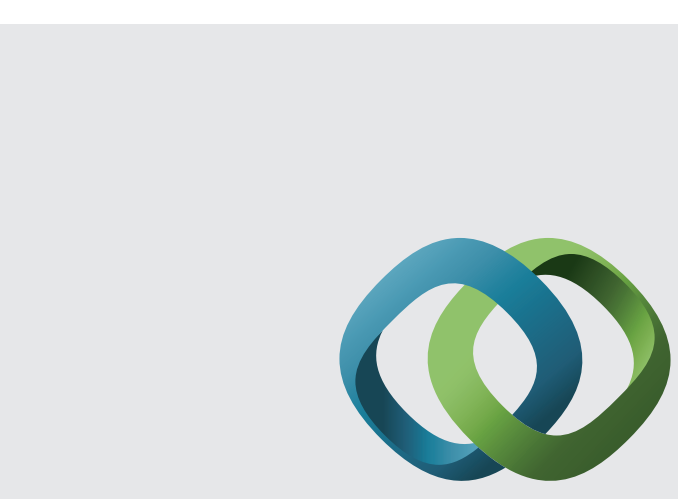

\section{Hindawi}

Submit your manuscripts at

http://www.hindawi.com
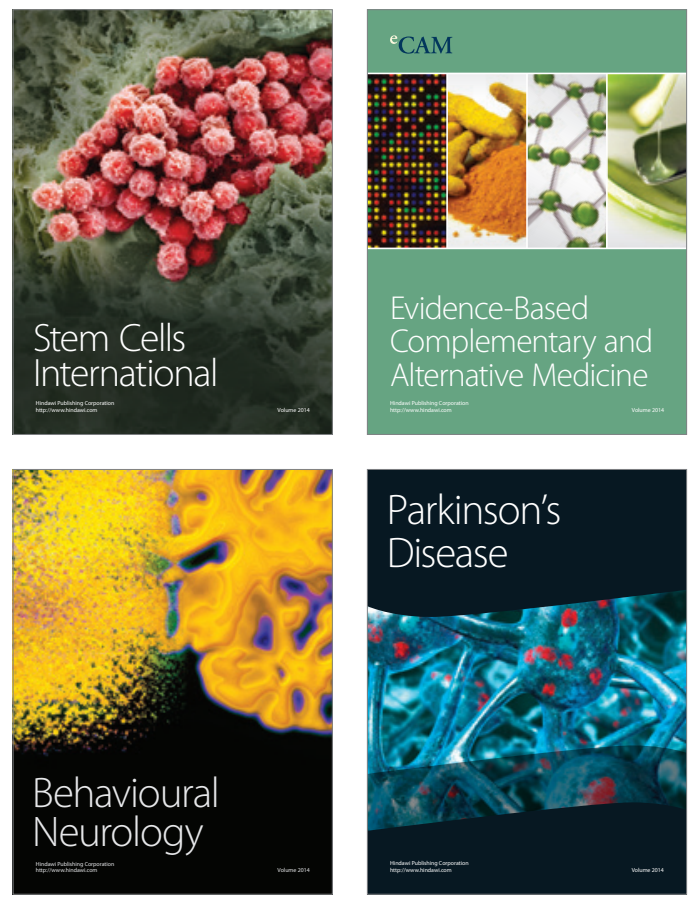
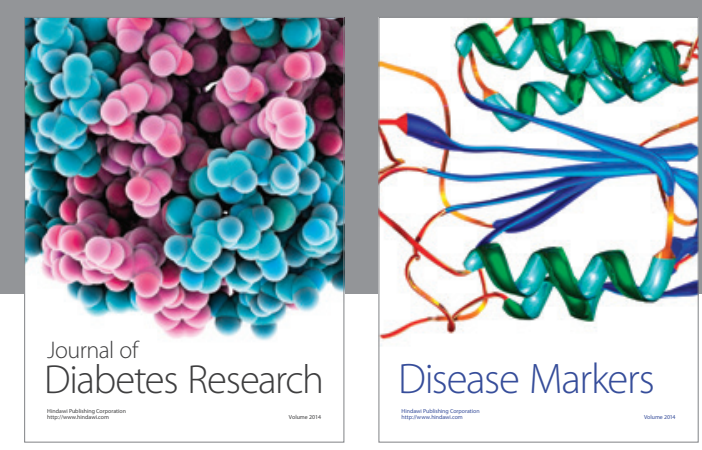

Disease Markers
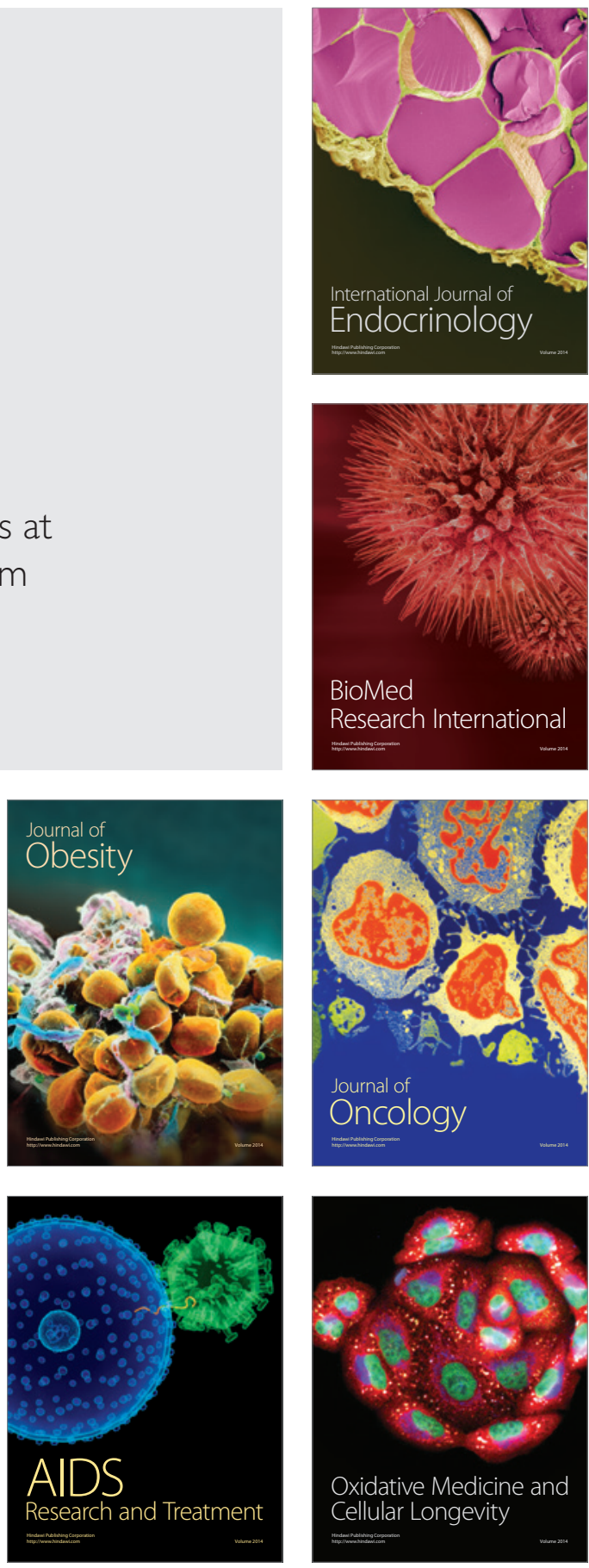